\title{
Optimum Retirement Age *
}

\author{
by Norma L. Larsen and August Ralston **
}

\section{Introduction}

This paper models optimum retirement age by considering both the demand for a human resource (expressed here as the demand for a particular employee $A$ ) and the supply of that human resource. Optimal retirement age is obviously a combination of the employer's offer to employ $A$ and $A$ 's willingness to be employed. These demand and supply sides of the retirement age question will be considered in this paper. However, the emphasis will be on the demand side. The supply side has previously received more attention by researchers $[1,6]$.

The paper uses a classical economic marginal analysis of the retirement age question and begins by assuming a competitive labor market. This assumption is soon relaxed to allow consideration of more realistic possibilities, including imperfect information, which may result in exploitation of employees, implicit labor contracts, and the like. Special attention is given to the impact of pension plans on the optimum retirement age.

\section{Marginal analysis of the supply side}

The optimum retirement age for an individual supplying labor is that age where the marginal benefits of continuing to work are equal to the marginal costs of continuing to work. When an individual reaches that age he or she no longer offers to labor. One recent formulation of this supply side optimum retirement age assumes that an individual has a fixed utility, $U=v$, from retirement (or leisure), independent of age [6]. Upon retirement, the individual loses an income of $w-b$ where $w$ is the pre-retirement wage and $b$ is the benefit received upon retirement from the pension plan. If the marginal utility of consumption is equal to the inverse of the level of

* The authors wish to express their thanks to Teivo Pentikainen whose comments on a paper presented at the 1980 Risk Theory Seminar led to the development of this paper and Karl Borch whose comments at the Eighth Seminar of the European Group of Risk and Insurance Economists improved the analysis.

** University of Southern California, Los Angeles. 
consumption $(c)$, the loss in terms of utility is equal to $c^{-1}(w-b)$. Thus, the individual's net marginal utility of postponing retirement, $U^{\prime}$, is equal to $U^{\prime}=c^{-1}(w-b)-v$. The first-order condition that determines the optimum supply side retirement age $\left(R_{s}\right)$ is therefore :

$$
U^{\prime}=c^{-1}(w-b)-v=0 .
$$

\section{Marginal analysis of the demand side}

The demand side of the optimum retirement age question involves the firm's offer to provide employment. The wage rate and pension plan benefit factors used in determining supply side optimum retirement age are important variables in determining demand side optimum retirement age $\left(R_{d}\right)$. One additional variable which must be considered is the productivity or contribution of an employee to the employer's profitability. The model being developed here assumes the quantities and qualities of other physical and human resources are known and discretely fixed with $A$ being the variable resource input. Marginal revenue product $\left(M R P_{A}\right)$ will be used as the measure of employee $A$ 's contribution. ${ }^{1}$

\subsection{The MRP function}

In the formulation which follows, $M R P_{A}$ is plotted against the age of $A$ even though it is recognized that other variables could be chosen to specify $M R P_{A}$. The decline being considered, then, is due to the aging process and independent of the marginal resources phenomenon. Even if the market price of output is positive, ultimately the marginal physical product $\left(M P P_{A}\right)$ will equal zero and therefore $M R P_{A}=0$. It is also assumed that $M R P_{A}$ is separable.

Although the specific task of $A$ is not defined here, learning theory indicates that $M R P_{A}$ may increase over the early portions of an employee's worklife. The employee's age at the beginning of employment is $X$ and the maximum $M R P_{A}$ is defined to occur at $M R P_{\max }$ before it begins to decline. The age, $R_{x}$, at which $M P P_{A}=0=M R P_{A}$ is late in life for most but may be reached relatively early by others. Professional athletes are examples of the latter. The $M R P_{A}$ function as described above is shown in Figure 1 (a).

\subsection{The wage function}

In a perfectly competitive labor market, $M R P_{A}=W_{A}$, the wage of employee $A$ at each point in time. Beyond $M R P_{\max }$ this would mean a decreasing wage with increasing age. A wage decreasing to zero is not realistic. In order to retain any

1 If a firm is in a perfectly competitive product market, $M R P_{A}$ equals the value of the marginal product $\left(V M P_{A}\right)$. If it is a monopolistic firm, $M R P_{A}<V M P_{A}$. Therefore, $M R P_{A}$ is more generally applicable and the model may be applied to any firm employing $A$ within the full range of perfectly competitive to purely monopolistic product markets. 
Figure 1: Optimum retirement age functions

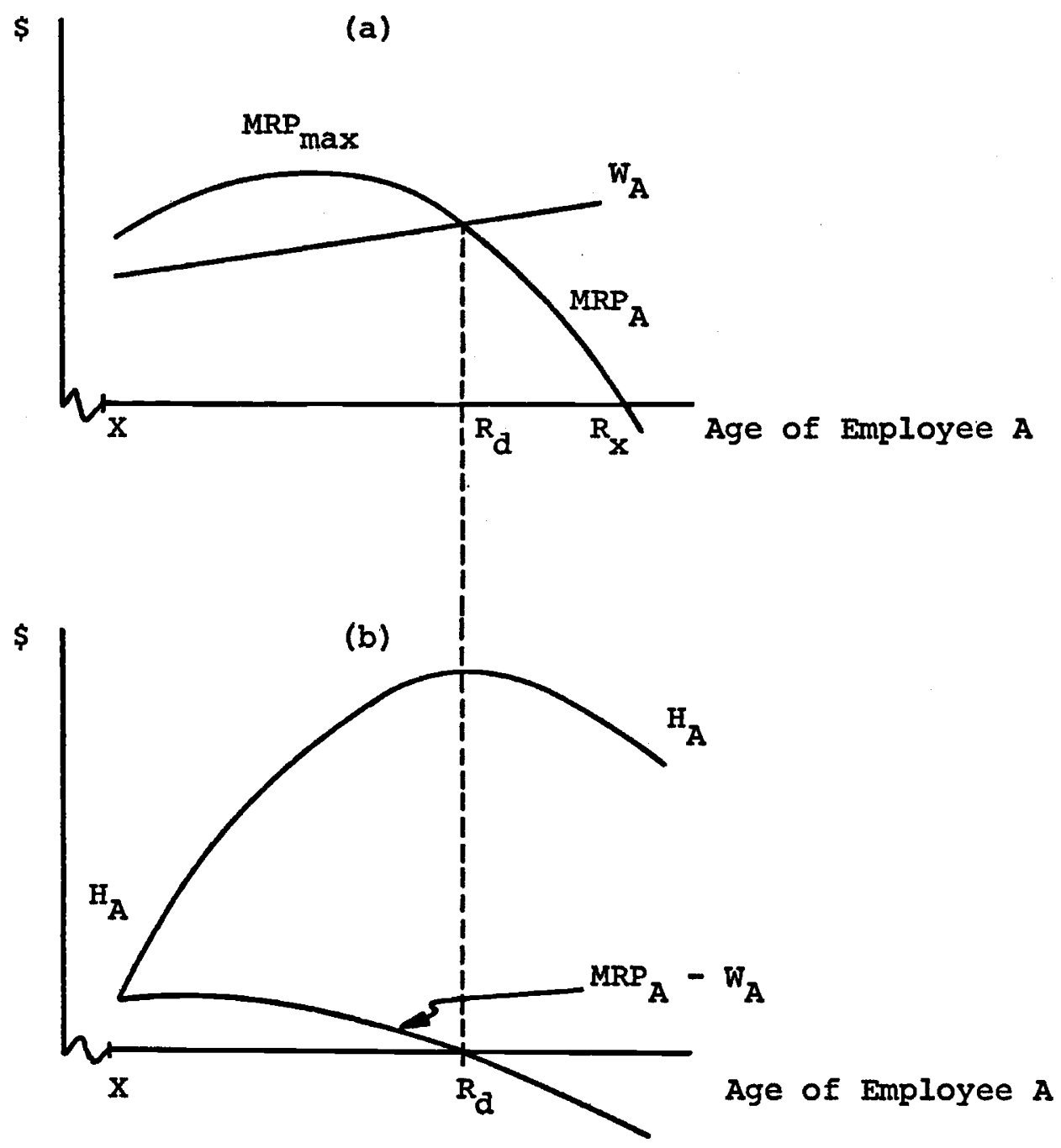


employee, the employer must be paying a wage which is equal to or greater than a subsistence wage and certainly greater than zero. Therefore, if $A$ is employed, the employer will desire to retire $A$ at an age earlier than $R_{x}$.

If we conclude that $M R P_{A}=W_{A}$ is an inadequate description of a wage pattern, the shape of the wage function is not obvious and must be defined by something other than the $M R P_{A}=W_{A}$ equality. Even if this equality does not hold, however, there exists a market wage, $W_{M}$, which $A$ could earn. This $W_{M}$ may be determined by many demanders and suppliers of labor or through explicit negotiation (i.e., collective bargaining). It should be noted that $W_{A}$ may be relatively fixed and therefore at times greater or less than $W_{M}$ because of an implicit labor contract [2]. In any event, $W_{A}$ will not be more than $W_{M}$ or more than $W_{M}$ plus the implicit wage contract premium $\left(W_{M}+\right)$. The employer would have to pay no more than that to employ any other worker.

Rimlinger [5] has argued that the wage $A$ actually receives, $W_{A}$, may be less than $W_{M}$ if a portion of the compensation is deferred in the form of a pension plan. The basic elements of the model are a set of income offer lines and a set of income indifference curves. The solution consists in finding take-home pay, pension, and contribution rates that are consistent with profit maximization and worker satisfaction. A graphic presentation of the model's solution illustrates the equilibrium consistent with the dual maximization condition. In Figure 2, the original equilibrium wage $W_{M}$

Figure 2

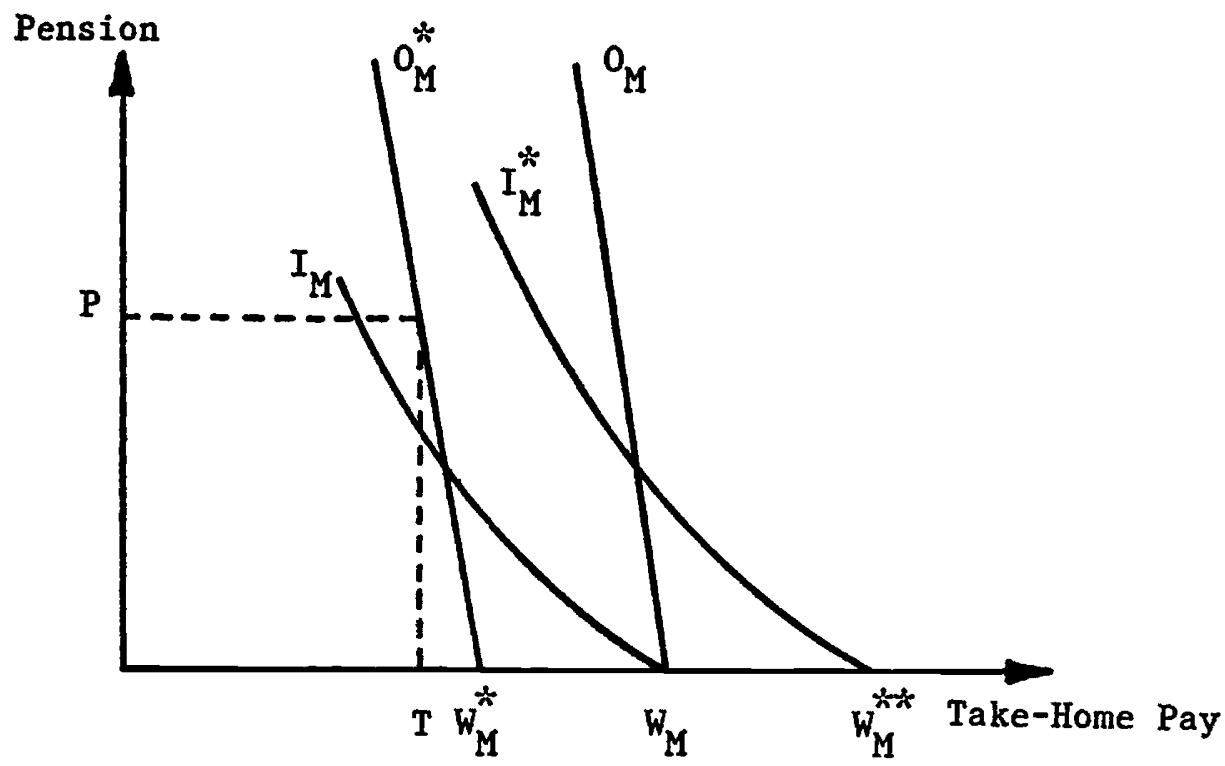


is translated into offer line $W_{M} O_{M}$ and the indifference curve $W_{M} I_{M}$. The only point they have in common is $W_{M}$. Therefore, if employers pay the wage $W_{M}$ they fail to maximize profit because they could hire the corresponding labor supply for a smaller outlay. Except for the $W_{M}$ point all pay-pension combinations on the $W_{M} I_{M}$ indifference curve are less expensive than the combinations on the $W_{M} O_{M}$ offer line. The equilibrium is reached where an offer line $\left(W_{M}^{*} O_{M}^{*}\right)$ is tangent to the indifference curve $\left(W_{M}^{*} I_{M}^{*}\right)$ for that same level of employment. Both $W_{M}$ and $W_{M}^{* *}$ correspond to the same level of labor demanded. The equilibrium pension is $P$, take-home pay is $T$, and the monthly contribution is $W^{*}-T$. These values satisfy the profit maximizing condition that wage equals the marginal revenue product : $T+\left(W^{*}-T\right)=W^{*}$. The introduction of the pension has reduced labor cost from $W_{M}$ to $W_{M}^{*}$ and increased effective compensation for workers from $W_{M}^{* *}$ to $W_{M}$. This follows from the difference in valuation that workers and employers put on compensation factors ([5] pp. 310-313).

$W_{M}^{*}$ may also reflect any implicit labor contracts, immobility, and discrimination characteristics in the market. With any of these imperfect market conditions we can make two other important assumptions. First, we may assume that monopsony does not exist, and therefore $W_{M}^{*}$ is equal to the marginal resource cost of $A$. That is, all employees identical to $A$ which the employer demands could be hired at $W_{M}^{*}$. Secondly, $A$ will not be paid more than $W_{M}^{*}$, since the employer could employ an identical employee for $W_{M}^{*}$ at the most. Therefore, the wage earned by $A, W_{A}$, is always $\leqslant W_{M}^{*}$. This follows directly from the first assumption.

\subsection{Optimum retirement age equilibrium using marginal analysis}

Given the marginal revenue product and recognizing the possible wage functions above, the accumulated value of employee $A$ to the employing firm at age $x+n, H_{A}(x+n)$ is generally described by

$$
H_{A}(x+n)=R \int_{n}^{\infty} f(t) d t+\int_{n}^{\infty}\left[\left(M R P_{A}(t)-W_{A}(t)\right][1-f(t)] e^{\delta(t-n)} d t\right.
$$

where

$W_{A}(t)=$ total compensation earned by $A$ in period $t ;$

$M R P_{A}(t)=$ marginal revenue product of employee $A$ in period $t$;

$R=$ replacement cost of employee $A$; i.e., the cost to the employer of a "breakdown" of employee $A$;

$f(t)=$ probability density function of a breakdown occurring at time $t$ which requires replacement of employee $A$;

$\delta=$ force of interest.

The cost of replacing $A$ includes expenditures of several different types. Obvious costs would be for recruiting, hiring, and training a replacement employee. Then termination costs, including any termination pay provided terminated employees and revenues lost during the time required to fill the position, are added to direct replacement costs to arrive at total replacement cost, which will be referred to in the above formulation as $R$. Presumably, a firm would desire that a replacement employee be 
of equivalent productivity to a terminating (including retiring) employee. If not, training costs would be incurred to upgrade the new employee.

The $H_{A}(x+n)$ function is shown in Figure $1(\mathrm{~b})$. The demand side optimum retirement age, $R_{d}$, is determined as that age where the accumulated value, $H_{A}(x+n)$, is maximized. This is achieved by setting the first derivative of equation (2)

$$
H_{A}{ }^{\prime}(x+n)=[R \cdot f(x+n)]+\left[M R P_{A}(x+n)-W_{A}(x+n)\right][1-f(x+n)] e^{\delta(n)}
$$

equal to zero. The optimum time to retire an employee, age $x$, is $n$ years following initial employment. This obviously occurs at age $x+n$ and is the first year in which the cost to the firm of allowing $A$ to work one year is greater than $M R P_{A}$.

\section{Pension plan design}

The structure of a pension plan has a primary impact on the magnitude of the retirement costs for an employee and on the incidence of those costs. The most important application of the theory being developed here is to facilitate the designing of the pension plan so that actual retirement coincides with optimum retirement age. Decisions as to whether the benefit formula will be final average or career average, whether years of service will be recognized, what the vesting schedule will be, and whether employees will be required/allowed to contribute are integral in determining the amount of pension benefits earned. This amount is combined through the application of an actuarial cost method to develop the retirement cost function. Therefore, each of these decisions - including the choice of the actuarial cost method - may have a direct impact on the retirement cost function and on the optimum retirement age.

Let us define the cost to the employer of employing $A$ as the present value of $A$ 's lifetime income to be provided by the employer. That is,

$$
I=\int_{x}^{\infty} \frac{W_{A}(t) e s(t-x)}{e^{\delta(t-x)}} d t
$$

where $W_{A}(x+n)=$ total compensation (wage) of employee $A$ at age $x+n$,

$x=$ age of entry into employment,

$\delta=$ force of interest,

$\boldsymbol{g}=$ assumed annual growth rate.

$I$ is a function of many variables with the most important being the wage earned by $A$ throughout the period. Whether $A$ 's wage is determined in a perfectly or imperfectly competitive labor market does not seem crucial. Of course, in perfectly competitive product and labor markets, $W_{A}$ would be viewed as random ; but, observation indicates experience and formal and informal work rules contribute to an increasing (or at least non-decreasing) $W_{A}$ as a function of age in nominal terms.

Having defined $I$ as the present value of $A$ 's lifetime income provided by the employer, it is reasonable to assume that the employer desires to minimize the cost of $I$ over the period of $A$ 's employment which is needed to purchase any given 
productivity level and may be willing to enter into labor contracts, explicit or implicit, in order to minimize this cost. If $R$ is the cost to the employer if a breakdown occurs, the expected cost, $Z$, to the employer if $A$ is to be replaced at time, $n$, is

$$
Z=I+R \int_{0}^{n} f(t) d t
$$

In order to minimize the average replacement $\operatorname{cost}(Z)$ of employing $A$ over the employing period, it is necessary to solve

$$
\min \left\{\frac{1}{n}\left(I+R \int_{0}^{n} f(t) d t\right)\right\}
$$

the solution is given by

$$
I=R\left\{n \cdot f(n)-\int_{0}^{n} f(t) d t\right\}
$$

The minimization of $l$ at $n$ years of employment corresponds to the age $x+n$ at which the employer would retire $A$. This minimization must generate a value which is equal to the value fixed for $M R P_{A}$, or less than the contribution of $A$ to the employer's earnings at each period $t$. If $M R P_{A}$ is actually greater than that assumed, a different $Z$ function would have to be solved. If the minimization of all $Z$ functions exceeds $M R P_{A}$, the employer would not use $A$ as a resource.

The optimum retirement age to this point is dependent upon an undivided or unallocated 1 . But, as shown earlier, $I$ must be allocated in order for the profit maximization assumption to hold with a portion of the wages earned by $A$ being deferred to $A$ 's retirement period. If a portion of $A$ 's wages are diverted to a pension plan, then we can rewrite the earlier formulation using

$$
\begin{aligned}
& C W_{A}(t)=\text { cash wages represented by a cash income stream to } A, \\
& R C(t)=\text { pension or retirement costs for } A \text {, and } \\
& \delta \quad=\text { force of interest. }
\end{aligned}
$$

Now, a feasible pension plan must satisfy

$$
I=\int_{0}^{\infty}\{C W(t)+R C(t)\} e^{\delta t} d t
$$

where the accumulated pension fund after $n$ years of employment is

$$
P(n)=\int_{0}^{n} R C(t) e^{\delta t} d t
$$

which will provide a perpetual income

$$
=\delta \int_{0}^{n} R C(t) e^{\delta t} d t
$$

The cost of retirement benefits, $R C_{A}(t)$, is the nominal value of the retirement benefits earned by $A$ from employment during the time period $n . R C_{A}$ does not represent funding levels for benefits; instead, it is best estimated by the chosen actuarial cost method. $A$ may even be funding a portion of this cost by deductions 
from cash wages and $R C_{A}$ for most employees will include the costs of a social pension as well as a private or public pension plan. ${ }^{2}$ All the arguments developed here apply equally to social as well as private pensions. In fact, Rimlinger's arguments were originally developed in the context of social insurance [5].

\subsection{Optimization}

Recognizing the components of $W_{A}$, equation (3) becomes

$$
H_{A}^{\prime}(n)=R \cdot f(t) d t+\left\{M R P_{A}(t)-\left[C W_{A}(t)+R C_{A}(t)\right]\right\} e^{\delta(t-n)}
$$

It can now be stated that the optimum retirement age is the first year of employment, $n$, in which the cost of allowing $A$ to accrue an additional year of retirement benefit equals or exceeds the non-retirement cost net benefit $\left(M R P_{A}-C W_{A}\right)$ to the firm of keeping the employee on the payroll. The optimum retirement age, $R_{d}$, is also defined as that year, $n$, in which

$$
\left(M R P_{A}(n)-C W_{A}(n)\right)+R \cdot f(n)=R C_{A}(n)
$$

Analytically, this is achieved by setting $H_{A}{ }^{\prime}(n)=0$.

The formulations above are illustrated in Figure 3. Figure 3 (a) demonstrates that $M R P_{A}(n)>W_{A}(n)$ until the employee reaches age $R_{d}$. The same optimum retirement age is illustrated in Figure 3 (b) ; $R_{d}$ is the age at which $R C_{A}=M R P_{A}-C W_{A}+R \cdot f(t)$. Figure 3 (b) illustrates that $H^{\prime}=0$ at $R_{d}$. $A$ should not be retained until age $R_{y}$ if pension benefit costs are correctly recognized.

The formulation for $R_{d}$ in Equation (10) is at a highly theoretical level. In reality, cash wages may be difficult to define and the $M R P$ function is difficult to observe. Only by knowing these variables is it possible to use the formulation of $R_{d}$ to have actual retirement age turn on a comparison of the cost of an additional year of retirement benefit accrual and $M R P_{A}(n)-C W_{A}(n)$.

The cost of retirement benefits, $R C_{A}(n)$, is defined as the cost of additional benefits to which the employee becomes entitled from working during the period. The shape of the $R C_{A}$ curve is not known at this point even though $R C_{A}$ is shown as a linear function in Figure 3. Only its value at $R_{d}$ is known. This separation of $R C_{A}$ from the other variables of equation (9) and (10) is useful, however, in isolating the impact of specific elements of pension plan design.

\subsection{Normal retirement age}

Every pension plan contains provisions concerning the retirement age of the covered employee. For example, most social, public, and private plans are constructed

2 A social pension plan encompasses all employees within a state or country whether or not they are employed by the government. An example would be the U.S. Social Security System which is funded through payroll taxes. A public pension plan covers employees of a government or quasi-governmental body; the plan is public in that it is funded through tax dollars. A private pension plan covers employees of a privately owned organization; the plan is funded through the revenues of that organization. 


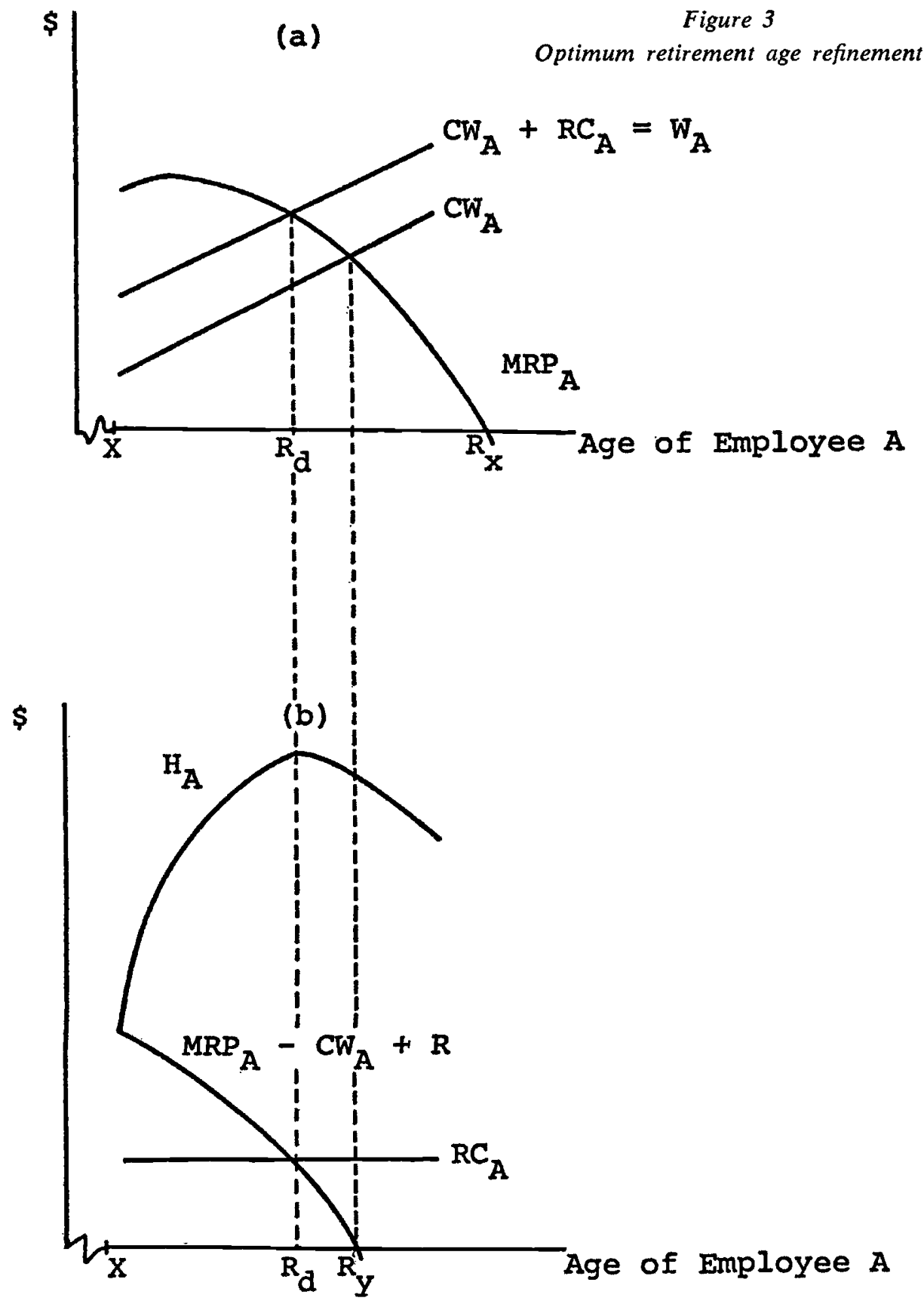


around a normal retirement age assumption. Benefit accruals, plan funding, and the allocation of plan costs are tied to a presumed retirement at the normal age, most commonly age 65 . In addition, a mandatory retirement age is imposed on many employees. The recently passed Age Discrimination Employment Act provides that no U.S. employer may mandate an age lower than 70 for retirement. Even this later mandatory retirement age - the minimum legal age previously was 65 - unquestionably deprives employers of some productive employees. Only by chance will a mandatory age or a normal age be an allocatively efficient retirement age.

A normal retirement age $(N R A)$ may be viewed as an assumed retirement age. Retirement is not necessarily required at that age. However, benefits earned and received upon retirement are usually reduced if retirement occurs before the $N R A$ is reached. Retirement beyond the $N R A$ usually means that retirement benefits received will be increased reflecting a shorter life expectancy. Benefit accruals may or may not continue beyond $N R A$ depending on pension plan provisions. The crediting of years of service may discontinue at the $N R A$ and for a benefit formula which include wages, plan provisions may prohibit the use of wages earned after the $N R A$. These provisions directly affect the realization of the optimum retirement age.

In any event, a $N R A$ for employee $A, N R A_{A}$, will not necessarily prevent the achievement of $R_{d}$. However, since $N R A_{A}$ is not a function of $M R P_{A}, C W_{A}$, or $R C_{A}$, there is no assurance that $N R A_{A}$ and $R_{d}$ will coincide. Instead, benefits earned and the actuarial cost method used to cost out those benefits and therefore $R C_{A}$ are dependent upon $N R A_{A}$. This means that given $N R A_{A}$ and all other pension plan provisions, $A$ should be retired at that age, $R_{d}$, where $R C_{A} \geqslant M R P_{A}-C W_{A} \cdot R_{d}$ may or may not be the same as $N R A_{A}$. Of course, in no event, should the $N R A_{A}$ assumption produce a $C W_{A}+R C_{A}=W_{A}>W_{M}^{*}$

\subsection{Contributory vs. noncontributory}

One must argue that in the case of a perfectly competitive labor market a mandatory (noncontributory) pension plan will have no impact on $R_{d}$. The cost of the pension plan is an amount which employees could receive currently in the form of higher cash wages but have chosen to defer. Clearly the total wage $W_{t}$ of an employee covered by this type of plan is precisely the $W_{M}$ he or she could earn in alternative employment where no retirement plan is provided.

On the other hand, the perfectly competitive labor market assumption is inadequate to dispel the impact of a pension plan on $R_{d}$ in the case of a voluntary contributory retirement plan with immediate vesting and level benefit accrual. Consider as an example a plan where the employer will contribute 10 percent of an employee's base pay to the pension if and only if the employee agrees to contribute five percent of his or her pay. In this case $W=C W=1$ and $R C=0$ if the employee decides not to participate in the plan. If the employee decides to participate in the plan he or she will receive $W=C W+R C=.95+.15=1.10$. A supply side analysis of these results implies that in the aggregate utility of $C W(.05)$ is less than or equal to the utility of $R C(.15)$. One can argue, therefore, that if the employees are deriving 
the same utility from $W$ regardless of the composition of $W$ no increase in overall productivity as a result of the availability of the pension plan can be expected. This conclusion is contrary to one of the traditional arguments for instituting a pension plan.

In the example just described, $R_{d}$ is definitely and directly affected by the pension plan as illustrated in Figure 3. If an employee elects to participate in the plan, thereby increasing his or her total compensation from $W_{t}$ to $W_{t}^{1}$, the employer will optimally choose to retire that employee earlier, i.e., at $R_{d}^{l}$ instead of $R_{d}$. This is not necessarily optimal for individual employees. Those employees electing to participate in the plan obviously are those whose $U\left[R C_{t}(.15) \geqslant U\left[C W_{t}(.05)\right]\right.$. The employee is almost certainly unaware of the effect of participation in the pension plan upon their value $\left(H_{A}\right)$ to the employer.

\subsection{Vesting provisions}

Similarly the vesting schedule can be shown to have a noticeable impact on $R_{d}$. The model must be modified to include a probability of surviving in employment for a period of time sufficient to receive retirement benefits. Amending the previous example to include ten-year vesting implies that an employee would select pension plan participation if and only if

$$
\left.{ }_{10-t t} p_{x+t}\right) U\left[R C_{t}(.15)\right] \geqslant\left[C W_{t}(.05)\right]
$$

where

${ }_{i j} p_{k}=$ probability of an individual age $k$ surviving in employment for $i$ years given that he or she has already survived for $j$ years; and

$x=$ the age at which the employee first participated in the pension plan.

The results of this simple 10-year vesting schedule are shown in figure 4 and are identical to the earlier case of immediate vesting except in the first 10 years of participation. Clearly $R_{d}=R_{d}^{1}$ if the employee does not continue with the employer for at least ten years and $R_{d} \geqslant R_{d}^{1}$ if the employee does survive in employment for at least ten years.

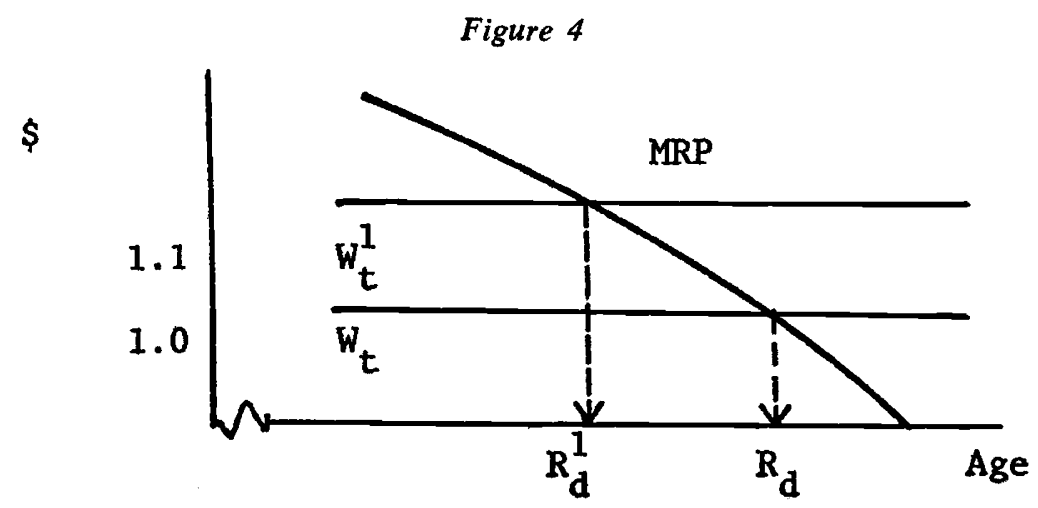


Other vesting schedules produce similar results ; for example, a $10 \%$ per year schedule would impact $R_{d}$ each year to a much smaller degree. A probability distribution of ${ }_{i j} p_{k}$ would be needed for each of the ten years required to achieve full vesting and each ${ }_{i j} p_{k}$ would be multiplied by the vesting percentage for the year. The participation decision in the earlier example becomes :

$$
\left.\begin{array}{r}
(t / 10)_{10-t t} p_{x+t} \text { for } t<10 \\
1 \text { for } t \geqslant 10
\end{array}\right\} \cdot U\left[R C_{t}(.15)\right] \geqslant U\left[C W_{l}(.05)\right]
$$

and the resulting graph of $R_{d}$ would have been a step-function $W_{t}$

\subsection{Actuarial cost method}

The actuarial cost method used in a pension plan is a major determinant of the costs of the pension plan which are assumed to accrue in a particular year. As such the actuarial cost method applied to a particular pension plan has a significant impact on the shape of the $R C_{A}$ curve.

For example, consider a defined benefit plan which is being instituted for a new employer. Since none of the firm's employees have any past service, no supplemental liability exists. The costs of this plan, expressed as a constant percentage of salary (CS), can be computed using either an accrued benefit cost method, ${ }^{C S} A B C M$, or a projected benefit cost method, CSPBCM. The $P B C M$ at a given point in time has recognized (accrued) a larger portion of the total cost of an individual employee's pension. See Figures 5 and 6.

Translating these characteristics into their impact on the $R C_{A}(t)$ function, the $A B C M$ results in a steeper slope than the $P B C M$. As shown in Figure 6, this causes a different optimum retirement age for any specific benefit accrual formula depending upon the cost method chosen. Only at age $X$, the participant's first year in the plan, and at the normal retirement age will $R C_{A B C M}=R C_{P B C M}$. This result occurs because the $A B C M$ recognizes that benefits earned at older ages (when only a few years remain to fund the benefit) are most costly.

\subsection{Other elements}

Other elements of plan design such as final average salary formula are certain to have interesting implications for $R_{d}$. These elements will be considered in a future paper.

\section{Policy Implications}

The theory and formulation of optimum retirement age can provide a great deal of insight for a pension plan designer. Implications are clear in the areas of mandatory retirement, negotiated retirement, and integration with Social Security. It in no way addresses the question that the benefits earned by age $R_{d}$ may be inadequate to meet the income replacement objectives established by the plan sponsors. 
Figure 5: Cumulative percentage of projected retirement benefit allocated to each age under various actuarial cost methods

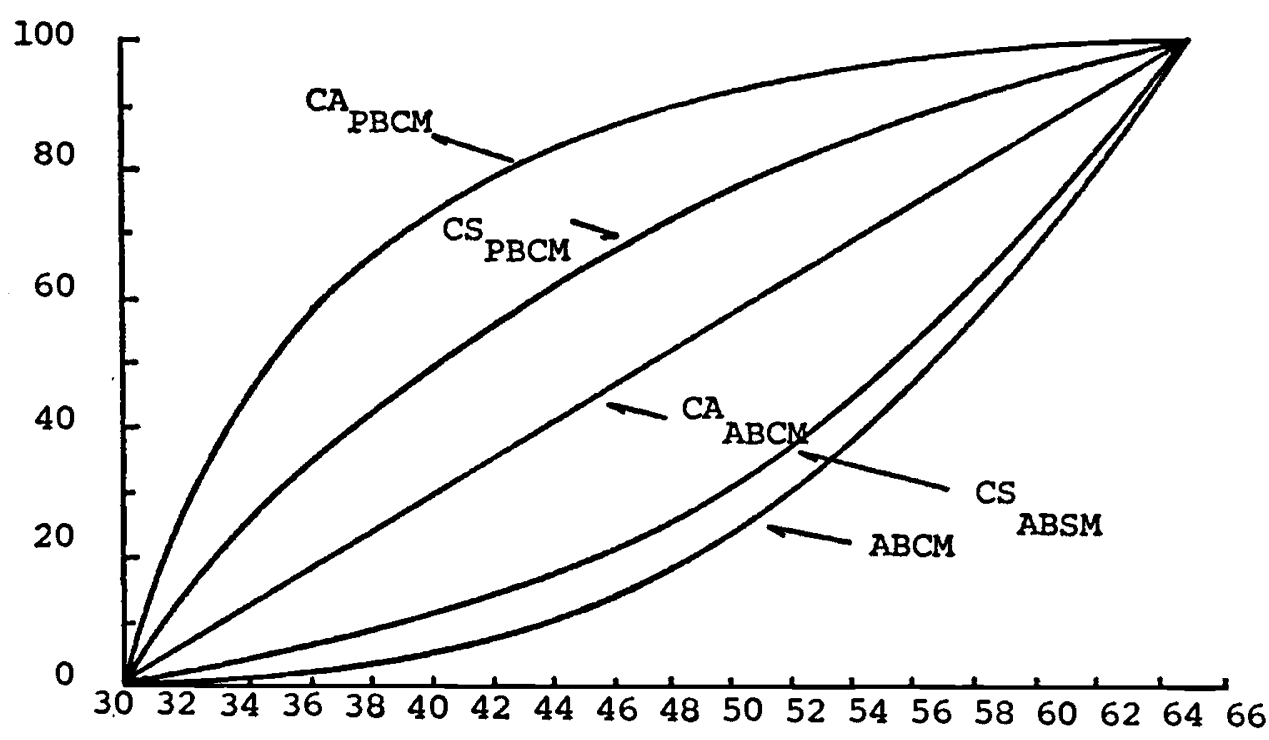

Source : Howard E. Winkelvoss, Pension Mathematics: With Numerical Illustrations (Pension Research Council 1977, p. 115).

Figure 6

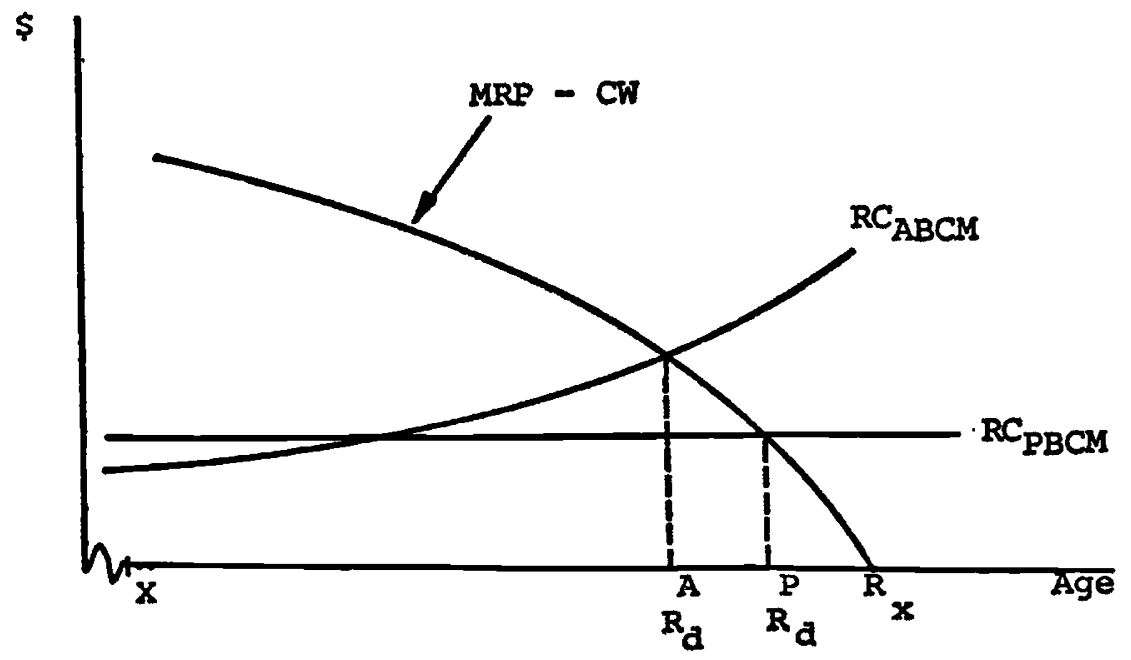


The misallocation of resources which may result from the imposition of a mandatory retirement age is shown in Figure 7. The optimum demand side retirement age, shown as $R_{d}$, is that age where the marginal value of the employee to the employing firm $M R P_{A}-W_{A}$ becomes zero. If a mandatory age is at $M$, or any other point to the left of $R_{d}$, the firm is being deprived of employing a human resource which has a positive value. The mandatory retirement age operates as a demand constraint with the $M R P_{A}-W_{A}$ function becoming $a b M$. Of course, if $M$ is to the right of $R_{d}, R_{d}$ will control.

Figure 7

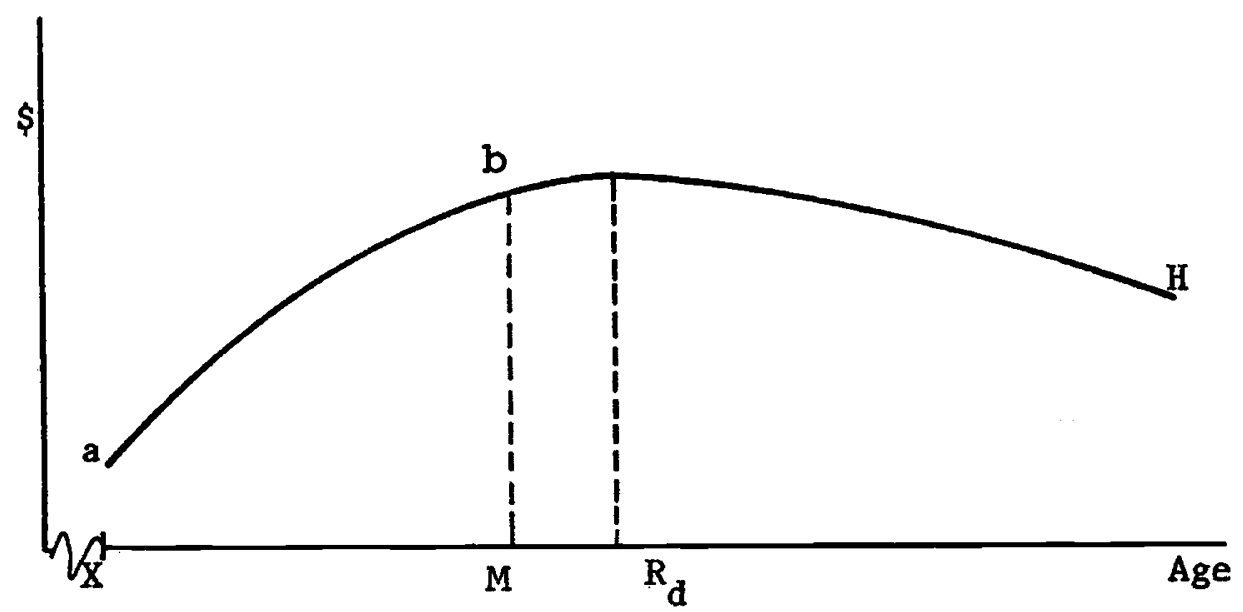

The employer can use the information provided by the optimum retirement age analysis in one of several ways.

(1) The employer should set the mandatory retirement age, $M$, as close as possible to $R_{d}$. The constraints imposed by the Age Discrimination Employment Act restrict the extent to which this is possible and does not address the problems created because individual employees have different $R_{d}$ 's.

(2) The Age Discrimination Employment Act requires $M \geqslant 70$. To the extent that $R_{d}<70$ and if employees are not, in fact, opting for retirement prior to age 70 , then the employer should search for cost effective measures to increase the productivity of workers in the $\left[R_{d}, M\right)$ set. This will increase the value of $R_{d}$ and minimize the number of employees and the loss resulting from those employees in $\left[R_{d}, M\right)$.

\subsection{Negotiated retirement}

The employer has the option of negotiating with individual employees or groups of employees to convince them to retire at $R_{d}$ even if $R_{d}<M$. The technique of "sweetening" early retirement benefits has been successfully applied by several firms facing economic problems as an alternative to massive layoffs. This way the retirees receive better pensions, more of the younger workers keep their jobs, and the employer avoids labor problems and higher unemployment insurance costs. 
For example, New Jersey's Public Service Electric and Gas Company received a less-than-adequate rate increase from the state utilities board in 1980. A special early retirement program was one elment of the cost-cutting program PSE\&G subsequently developed. Some 2,120 employees age 55 and over are eligible to take an unreduced early retirement plus a pension supplement until age 65 . The supplement is a severance pay of a flat $\$ 500$ per month, increasing by $\$ 50$ per month every three years, to be paid out of the utilities' general assets. Within ten days after the plan was announced, more than 700 employees applied for early retirement. This is twice the number of PSE\&G employees who would normally have been expected to retire in an entire year. Overall, more than 1,200 employees, about 80 percent of whom were union employees, retired under the special retirement program. The average age of those employees accepting the special early retirement offer was 59 [3].

\subsection{Integration with social security}

The employer may include the cost of Social Security in the $R C_{A}$ function together with the costs of various levels of benefit (or cost) integration. By including all these variables and observing the effect on the $R_{d}$ variable, the plan designer can choose that type of integration formula which results in an optimum retirement age closest to the actual retirement age expected or observed in the employee population.

\section{Conclusion}

The purpose of this paper has been to consider the retirement of employee $A$ within a resource allocation context. Retirement was approached from the demand side which involves the employer's offer to provide employment to $A$ as opposed to $A$ 's willingness to be employed.

The marginal revenue product of $A\left(M R P_{A}\right)$ was used to measure $A$ 's contribution to the firm and the wage of $A$ ( $\left.W_{A}\right)$ measured the cost to the firm of employing $A$. These variables were described as dependent on the aging process of $A$. Given $M R P_{A}$, $W_{A}$, and costs to replace $A(R)$, the optimum demand side retirement age, $R_{d}$, is determined by maximizing $H_{A}(x+n)$. $H_{A}(x+n)$ is the value of employee $A$ to the firm. $R_{d}$ is the age $x+n$ and is the first year in which the cost to the firm of allowing $A$ to work one more year is greater than $M R P_{A}$.

Since most employees are covered by pension plans, it was important to consider their impact on optimum retirement age. In the model, retirement benefits earned were treated as deferred wages. The wage variable became cash wages plus the cost of retirement benefits earned or $C W_{A}(n)+R C_{A}(n)$. It follows that the optimum retirement age can be stated as the first year, $x+n$, in which the cost of allowing $A$ to accrue an additional year of retirement benefit equals or exceeds the nonretirement cost net benefit, $M R P_{A}(t)-C W_{A}(t)$. With this formulation, the model is convenient for looking at pension plan design questions and other policy implications.

It was shown that the use of a normal retirement age assumption in pension plans will neither prevent nor assure the achievement of $R_{d}$. The choice made by an 
employee in a voluntary contributory plan and vesting schedule will affect the optimum age. And, because they affect the shape of the $R C_{A}$ function, actuarial cost methods influence $R_{d}$. Further, the model was used to demonstrate the misallocation of resources which may be associated with a mandatory retirement age and the basis for negotiated retirement.

The authors believe the model formulated in this paper represents a new approach to considering retirement age. The optimum retirement age theory presented, hopefully, will be of interest to other researchers and encourage further refinements. A next step may be to fully model the integration of the supply side and demand side of employment where pension plans are involved. Also, the model may provide a useful structure for empirical research required to deal with a variety of retirement and pension questions.

\section{REFERENCES}

1. DIAMOND, P. A., and MIRRLEES, J. A.: " A model of social insurance with variable retirement ", Journal of Public Economics, 10 (December 1978), 295-336.

2. DREZE, J. H.: "Human capital and risk-bearing", The Geneva Papers on Risk and Insurance, No. 12 (June 1979), 5-22.

3. "Early retirement incentives used to cut costs", Employee Benefit Plan Review (November 1980), 44-92.

4. LARSEN, N. L., and RALSTON, A.R.: "Human assets and risk management", forthcoming in Journal of Risk and Insurance.

5. RIMLINGER, G.V.: Welfare Policy and Industrialization in Europe, America, and Russia, John Wiley \& Sons, New York, 1971.

6. SHESHINSKI, E. : "A model of social security and retirement decisions", Journal of Public Economics, 10 (December 1978), 337-360.

7. WINKELVOSS, H.E.: Pension Mathematics: With Numerical Illustrations, Pension Research Council, 1977. 